\title{
Epidemiology of Cancer in Rural Congo: Case of IME Kimpese Hospital, Democratic Republic of Congo
}

\author{
Ngwala Philippe Lukanu ${ }^{*}$, Ngangu Patrick Ntontolo1,2, Vainqueur Diakengua1, \\ Chanel Kalombo ${ }^{1}$, Junior Nyambu ${ }^{1}$, Junior Landu ${ }^{1}$, Patricia Atungu ${ }^{1}$, \\ Zele Samuel Nsiangana ${ }^{2}$, Aliocha Nkodila ${ }^{1}$
}

${ }^{1}$ Family Medicine and Primary Health Care department, School of Medicine, Protestant University of Congo, Kinshasa, Democratic Republic of Congo

${ }^{2}$ Institut Médical Evangélique de Kimpese, Kongo Central, Republic Democratic of Congo

Email: *phlukanu@yahoo.fr

How to cite this paper: Lukanu, N.P., Ntontolo, N.P., Diakengua, V., Kalombo, C., Nyambu, Jr., Landu, Jr., Atungu, P., Nsiangana, Z.S. and Nkodila, A. (2021) Epidemiology of Cancer in Rural Congo: Case of IME Kimpese Hospital, Democratic Republic of Congo. Journal of Cancer Therapy, 12, 127-135.

https://doi.org/10.4236/jct.2021.123014

Received: February 2, 2021

Accepted: March 19, 2021

Published: March 22, 2021

Copyright $\odot 2021$ by author(s) and Scientific Research Publishing Inc. This work is licensed under the Creative Commons Attribution International License (CC BY 4.0).

http://creativecommons.org/licenses/by/4.0/ (c) (i) Open Access

\begin{abstract}
Background and Aim: Cancer is a public health problem in developing countries. It is aggravated by diagnostic confirmation difficulties. The aim of this study was to determine the epidemiological profile of cancers in Congolese rural areas. Methods: A historical cohort study was conducted with 914 histopathological protocols at the IME/Kimpese hospital from January 2008 to December 2013. Results: The mean age of patients was $55.2 \pm$ 14.5 years, and $61.9 \%$ were women with a sex ratio of $2 \mathrm{~W} / \mathrm{M}$. Ductal carcinoma (23.6\%), squamous cell carcinoma (23.5\%) and adenocarcinoma (23.1\%) were the most common cancers. The most affected organs were breast (26.3\%) and prostate (14.3\%). $41.5 \%$ of cancers had an undifferentiated character and more than half $(51.1 \%)$ a differentiated character. The majority of this cancer infiltrated other organs (57.9\%). Among cancers where grade was found, 16\% and $10.8 \%$ were respectively grades 1 and 4 , and the presence of metastases was observed in $10.9 \%$ of cancers. Conclusion: Cancer is more frequent in elderly women with a predominance of squamous and ductal carcinoma. The presence of a national cancer registry is necessary in the country for a good follow-up of cancer cases.
\end{abstract}

\section{Keywords}

Cancer, Epidemiology, Rural Area, Democratic Republic of Congo

\section{Introduction}

Cancer is one of the leading causes of death in adults. One over ten deaths is 
attributable to cancer worldwide [1] [2]. Cancers that were previously rare and considered as the diseases of high-income countries (HIC), such as colon, breast, and lung cancers, are now frequently diagnosed in low- and midle-income countries (LMICS) or economically transitioning countries and their rates are on the rise [3] due to increases in smoking, excess body weight, and physical inactivity. LMICs also have a disproportionate burden of infection-related cancers [4]. Cancer care is rapidly becoming a public health priority in sub-Saharan Africa. Up to $70 \%$ of the predicted 24 million people that will be diagnosed with cancer annually by 2050 will reside in LMICs [5].

In 2012, there were approximately 14 million new cases and 8.2 million cancer-related deaths (or $14 \%$ of deaths). More than $60 \%$ of new cancer cases occur in Africa, Asia, Central America and Latin America. These regions account for $70 \%$ of cancer deaths worldwide [1]. It is estimated that the number of new cancer cases per year worldwide is expected to increase from 14 million in 2012 to nearly 22 million in 2030 [6]. Epidemiological studies related to cancer come mainly from HICs and have made it possible to establish some risk factors with particular link to lifestyle [1]. Currently in Africa, anarchic urbanization, the food transition, and changes in lifestyle create optimal conditions for the emergence of chronic non-communicable diseases, including cancer, which here and there give an epidemic appearance [1] [2]. Among the implicated factors are smoking, alcohol consumption, sedentary lifestyle, low-fiber diets, as well as changes in reproductive life [6] [7] [8]. The lack of epidemiological transition between communicable and non-communicable diseases in developing countries is at the origin of an awakening of consciousness and justifies the development of effective prevention strategies. These require in advance, reliable surveys are able to indicate the main levels and risk factors specific to each environment, with a view to targeted reactions. Cancer registries available in most HICs and absent in most LMICs are a key tool in this approach [9]. The few fragmentary data available in our environment at the present time come from hospital surveys, where histopathological analyzes are available. The continuous cancer records published to date in our country are those from a survey conducted in Katanga, South Kivu, between 1983 and 1986 [10] and at the provincial referral hospital of Kinshasa [11]. This study is a response to the lack of cancer data in the Kongo-Central province and aims to determine the epidemiological profile of cancers in Congolese rural areas.

\section{Patients and Methods}

This study is a historical cohort study of data on patients with cancer, carried out at the IME Kimpese Hospital, Kimpese Health Zone in Kongo-Central province. IME-Kimpese is the only Hospital in the province with Histopathology service, during the period from January 2008 to December 2013. Patients received at IME Kimpese Hospital during the study period with suspected cancer and benefit a histopathological examination was carried out. An exhaustive 
non-probability and convenience sample of 914 patients was performed.

Data collection was carried out by researching the parameters of interest in histopathology protocols and consisted of finding all the histopathology protocols carried out at the IME-Kimpese Hospital in Kimpese Health Zone, during the study period. Any protocol with a diagnosis of benign or incomplete information was excluded. A special effort has been made to avoid multiple registrations. A systematic collection of patient details was introduced in an Excel 2010 file. If the same identification appeared more than once, the data were compared to verify if it was not the same person. If so, the information was being compiled on behalf of a single subject. In the event of a mismatch of information, the corresponding data were considered unusable for the study.

The following informations were systematically collected: socio-demographic characteristics (age, sex), data on the sample (nature of the sample, the origin site of the sample) and the histopathological diagnosis.

\section{Statistical Analysis}

Data were first encoded and validated before being entered into the computer, using Microsoft Excel 2013 software. Thereafter, the analyses were carried out with SPSS for Windows version 22 software. The descriptive analyses included the mean, standard deviation for quantitative data with Gaussian distribution and the absolute and relative frequencies for categorical data. Pearson's Chi-square test or Fisher's exact test was used to compare proportions and Student's t-test was used to compare the means. Logistic regression was used to find the risk degree of metastasis of each organ in multivariate analysis with calculation of the adjusted OR with $95 \%$ confidence interval. For all the tests used, the $\mathrm{p}$-value $<0.05$ was considered as the threshold of statistical significance.

\section{Ethical Approval}

This research was conducted in strict compliance with the recommendations of the Helsinki Declaration III. Permission to explore data from the histopathology service has been obtained from the Medical Director of the Hospital, and the commitment to respect confidentiality through anonymous collection was required.

\section{Results}

1) Patients with cancer by age and sex. The sample consisted of 566 women (61.9\%) and 348 men (38.1\%) with a mean age of $55.2 \pm 14.5$ years with the extremes ranging from 2 to 97 years old. The majority of patients were over 60 years of age (52.6\%). Figure 1 is showing that the frequency of cancer increased with age regardless of gender.

2) Cancer Profile. The most frequent histological features of the cancers found were ductal carcinoma (23.6\%), squamous cell carcinoma (23.5\%) and adenocarcinoma (23.1\%). Regarding the organ, $26.3 \%$ of cancers were associated 


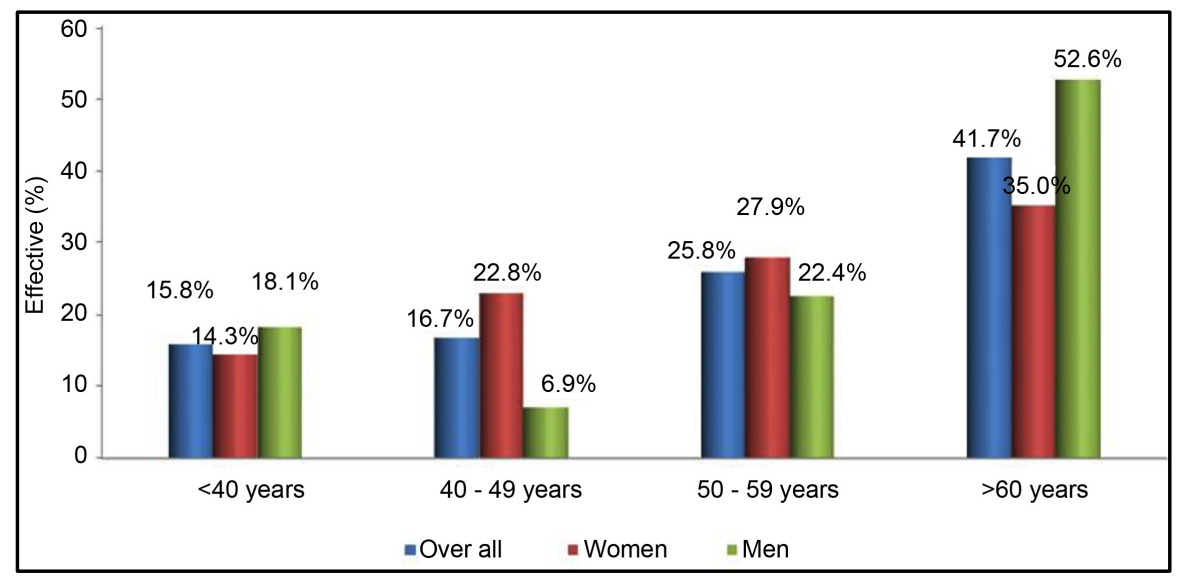

Figure 1. Study population with cancer by age and sex.

with the breast, followed by the prostate (14.1\%) and the cervix (13.2\%) (Table 1).

3) Characteristics of the tumor. Of all the protocols collected, $41.5 \%$ had an undifferentiated character and more than half (51.1\%) a differentiated character. The majority of cancers infiltrated other organs (57.9\%). Among the cancers whith grade recorded, $16 \%$ and $10.8 \%$ were respectively grade 1 and 4 , and the presence of metastases was observed in $10.9 \%$ of cancers (Table 2).

The histological characters of cancers did not show any significant difference according to age except ductal carcinoma which was higher in patients between 40 - 49 years old and prostatic carcinoma higher in patients over 60 years old $(\mathrm{p} \leq 0.001)$ (Table 3$)$.

It was observed among female patients, a predominance of breast cancer (41.3\%), followed by cervix (21.4\%) and colo-rectum (6.9\%) cancer. In contrast, in men, prostate (37.1\%) and colorectal (17.7\%) cancer predominated (Table 4).

Inguinal lymph node cancer had 31 times the risk of mestasis (aOR 31.43 95\% CI: $6.89-44.12, \mathrm{p}<0.001$ ), risk of metastasis was multiplied by 6 for liver cancer (aOR: 6, 36 95\% CI: $2.45-9.87, \mathrm{p}<0.001$ ), by 3 for bladder cancer (aOR: 2.73 $95 \%$ CI: $1.14-5.69, \mathrm{p}=0.015$ ), by 2 respectively for ovarian cancer (aOR: 2.35 $95 \%$ CI: $1.85-6.58, \mathrm{p}=0.015$ ) and bone cancer (aOR: 2.35 95\% CI: 1.12 - 5.25, $\mathrm{p}=0.023$ ). (Table 5) Furthermore, prostate cancer reduced the risk of metastasis by 3 (aOR: $0.4095 \%$ CI: $0.21-0.69, \mathrm{p}=0.001$ ).

\section{Discussion}

The objective of this study was to determine the epidemiological profile of cancers in Kimpese Health Zone which is a Congolese rural area. The current study found a predominance of cancer in females (61.9\%), and this profile is consistent with the epidemiological data reported by Mashinda et al. [12] in urban hospitals of Kinshasa. Many other African researchers have also mentioned the same epidemiological trend [13]-[18]. This predominance may be linked to hormonal factors which play a preponderant role in the genesis of cancers [19]. More than 
Table 1. Histological characteristics of cancers and affected organs.

\begin{tabular}{lclc}
\hline \multicolumn{2}{c}{ Histological characteristics of cancers } & \multicolumn{2}{c}{ Affected organs } \\
\hline Ductal carcinoma & $\mathrm{n}(\%)$ & & $\mathrm{n}(\%)$ \\
Squamous caracinoma & $216(23.6)$ & Breast & $240(26.3)$ \\
adenocarcinoma & $215(23.5)$ & Prostate & $129(14.1)$ \\
Prostatic carcinoma & $211(23.1)$ & Cervix & $121(13.2)$ \\
Leeberkuhnier type adenocarcinoma & $126(13.8)$ & Colorectum & $90(9.8)$ \\
Diffuse lymphoma & $62(6.8)$ & Bone & $64(7.0)$ \\
Fisiform cell sarcoma & $15(1.6)$ & Stomach & $41(4.5)$ \\
Kaposi's angiosarcoma & $15(1.6)$ & Face & $41(4.5)$ \\
Epitheloid leimyosarcoma & $11(1.2)$ & Endometrium & $34(3.7)$ \\
Meningothelial meningioma & $6(0.7)$ & Inguinal lymph node & $28(3.1)$ \\
Osteosarcoma & $6(0.7)$ & Left ovary & $18(2.0)$ \\
Tubulovillous adenoma & $6(0.7)$ & Liver & $16(1.8)$ \\
Cholangiocarcimoma & $4(0.4)$ & Lung & $16(1.8)$ \\
Serous cystadenoma & $3(0.3)$ & Skin & $12(1.3)$ \\
Nephroblastoma & $3(0.3)$ & Bladder & $12(1.3)$ \\
Psoriasis & $3(0.3)$ & Esophagus & $10(1.1)$ \\
Authentic seminome & $3(0.3)$ & Pancreas & $7(0.8)$ \\
Mixed oligoastrocytoma tumor & $3(0.3)$ & Parotid & $7(0.8)$ \\
Neuroendocrine tumor & $3(0.3)$ & Thyroid gland & $6(0.7)$ \\
& $3(0.3)$ & Vulva & $6(0.7)$ \\
& & Vagina & $4(0.4)$ \\
& & Larynx & $3(0.3)$ \\
& & Palace & $3(0.3)$ \\
& & Kidney & $3(0.3)$ \\
& & & $3(0.3)$ \\
\hline
\end{tabular}

Table 2. Specific characteristics of cancers.

\begin{tabular}{lcc}
\hline Characteristics of the tumor & $\mathbf{n}=914$ & $\%$ \\
\hline Differentiation & 379 & 41.5 \\
Undifferentiated & 68 & 7.4 \\
moderately differentiated & 467 & 51.1 \\
Well differentiated & & \\
Infiltration & 385 & 42.1 \\
No & 529 & 57.9 \\
Yes & & \\
Stage & 146 & 16.0 \\
stage 1 & 79 & 8.6 \\
stage 2 & 99 & 10.8 \\
stage 4 & 30 & 3.3 \\
stage 5 & 560 & 61.3 \\
missing & & \\
Presence of metastasis & 814 & 89.1 \\
Absent & 100 & 10.9 \\
Present & & \\
\hline
\end{tabular}


Table 3. Histological character according to age.

\begin{tabular}{lccccc}
\hline $\begin{array}{l}\text { Histological characteris- } \\
\text { tics of cancer }\end{array}$ & $\begin{array}{c}<\mathbf{4 0} \text { years } \\
\mathbf{n}=\mathbf{1 4 4}\end{array}$ & $\begin{array}{c}\mathbf{4 0}-\mathbf{4 9} \text { years } \\
\mathbf{n}=\mathbf{1 5 3}\end{array}$ & $\begin{array}{c}\mathbf{5 0}-\mathbf{5 9} \text { years } \\
\mathbf{n}=\mathbf{2 3 6}\end{array}$ & $\begin{array}{c}>60 \text { years } \\
\mathbf{n}=\mathbf{3 8 1}\end{array}$ & $\mathbf{p}$ \\
\hline Squamous cell carcinoma & 26.7 & 25.0 & 30.1 & 18.6 & 0.164 \\
Ductal carcinoma & 26.7 & 39.6 & 31.5 & 11.9 & $\mathbf{0 . 0 0 2}$ \\
Adenocarcinoma & 22.2 & 20.8 & 17.8 & 22.9 & 0.881 \\
Prostatic carcinoma & 2.2 & 0.0 & 5.5 & 31.4 & $<0.001$ \\
Leeberkuhnian & 11.1 & 4.2 & 9.6 & 4.2 & 0.116 \\
adenocarcinoma & 4.4 & 0.0 & 2.7 & 0.8 & 0.417 \\
Diffuse lymphoma & 2.2 & 4.2 & 1.4 & 0.8 & 0.392 \\
Spindle cell sarcoma & & & &
\end{tabular}

Table 4. Distribution of cancers by location and sex.

\begin{tabular}{lcclcc}
\hline & \multicolumn{2}{c}{ Female } & & \multicolumn{2}{c}{ Male } \\
\hline Organes & $\mathrm{n}=566$ & $\%$ & Organes & $\mathrm{n}=348$ & $\%$ \\
\hline Breast & 234 & 41.3 & Prostate & 129 & 37.1 \\
Cervix & 121 & 21.4 & Colorectum & 51 & 14.7 \\
Colorectum & 39 & 6.9 & Bone & 39 & 11.2 \\
Endometrium & 34 & 6.0 & Stomach & 33 & 9.5 \\
Face & 29 & 5.1 & Inguinal lymph node & 21 & 6.0 \\
Bone & 25 & 4.4 & Face & 12 & 3.4 \\
Left ovary & 18 & 3.2 & Liver & 9 & 2.6 \\
Lung & 10 & 1.8 & Breast & 6 & 1.7 \\
Stomach & 8 & 1.4 & Lung & 6 & 1.7 \\
Liver & 7 & 1.2 & Skin & 6 & 1.7 \\
Inguinal lymph node & 7 & 1.2 & Bladder & 6 & 1.7 \\
Skin & 6 & 1.1 & Esophagus & 6 & 1.7 \\
Bladder & 6 & 1.1 & Thyroid gland & 6 & 1.7 \\
Vulva & 6 & 1.1 & Pancreas & 3 & 0.9 \\
Esophagus & 4 & 0.7 & Parotid & 3 & 0.9 \\
pancreas & 4 & 0.7 & Larynx & 3 & 0.9 \\
Parotid & 4 & 0.7 & Palace & 3 & 0.9 \\
Vagina & 4 & 0.7 & Kidney & 3 & 0.9 \\
& - & - & Left testicle & 3 & 0.9 \\
\hline & & & & &
\end{tabular}

half of patients with cancer were over 60 years old (52.6\%), which is a logical consequence of the fact that the frequency of cancer increases with age irrespective of the gender. This trend was observed by Osama et al. who confirmed the relationship already established in the literature between age and cancer in a study conducted in LMICs [20].

Regarding the affected organ, our study found a high frequency of breast, prostate, cervix and colon cancer. Breast cancer ranks first and cervical cancer second among women. In Mashinda's study, cervical cancer ranked first, followed by breast cancer [12]. The predominance of breast cancer over cervical 
Table 5. Degrees of risk of cancer metastasis according to the organ affected.

\begin{tabular}{lcccc}
\hline \multirow{2}{*}{ Variables } & \multicolumn{3}{c}{ Matastasis } & \\
\cline { 2 - 5 } & Absent (\%) & Present (\%) & Adjusted OR (95\% CI) & p-value \\
\hline Inguinal lymph node & 0.7 & 22.0 & $31.43(6.89-44.12)$ & $<0.001$ \\
Liver & 1.1 & 7.0 & $6.36(2.45-9.87)$ & $<0.001$ \\
Bladder & 1.1 & 3.0 & $2.73(1.14-5.69)$ & 0.011 \\
Left ovary & 1.7 & 4.0 & $2.35(1.85-6.58)$ & 0.015 \\
Bone & 6.1 & 14.0 & $2.30(1.12-5.25)$ & 0.023 \\
Stomach & 4.7 & 3.0 & $1.15(0.65-1.58)$ & 0.258 \\
Colorectum & 9.7 & 11.0 & $1.13(0.21-2.11)$ & 0.489 \\
Breast & 26.3 & 26.0 & $1.10(0.14-1.44)$ & 0.897 \\
Endometrium & 3.7 & 4.0 & $1.08(0.26-1.98)$ & 0.987 \\
Prostate & 15.1 & 6.0 & $0.40(0.21-0.69)$ & 0.001 \\
\hline
\end{tabular}

cancer was also observed by Parkin et al.; they noted that in most countries of sub-Saharan Africa the incidence of breast was almost the double of cervical cancer [16]. In their study, Ngendahayo et al. observed that the difference between both organs is much smaller [21]. This could be a relative underestimation of cervical cancer, as many patients with cervix cancer present at a very advanced stage and a biopsy is not always done.

The incidence of Prostate cancer found in this study remains as predominant as the one reported by Ngendahayo et al. [21] and Mashinda et al. [12] even though the trend appears to be higher in the lattest study. The methodological difference could be the main element of this observed difference. Colorectal cancers were observed in $8.9 \%$ of patients, which is higher than that of Mashinda et al. in urban settings [12]. The presence of risk factors due to population poverty could explain the high frequency of this cancer in rural areas. Stomach cancer is the 5th most diagnosed cancer, high than Mashinda et al. findings but similar with study conducted in Rwanda [21]. In Africa this tumor appears to be quite common in West Africa and East Africa [16] [22] [23]. Food and alcohol consumption may promote and amplify a mitotic cascade in stomach cells and cause them to proliferate. In our series, liver cancer appears to be low (1.8\%). These results are similar to those observed by Kadende et al. in Burundi and Banda et al in Malawi [24] [25], Mashinda et al. in urban areas of the DRC [11] and Wabinga et al. in Uganda, found that the frequency of liver cancer was rather fluctuating [16]. In the specific characteristics of the cancers recorded, it was noted that about $11 \%$ of the cancers had metastasized. These metastases were significantly higher in lymph node, bone, liver, bladder and ovarian cancer. As these organs are known to be the most vascularized and maintain direct communication with other organs, they could facilitate the reaching of distant organs through this blood communication [26].

\section{Strengths and Limitations}

We conducted a rigorous investigation in order to reduce the impact of biases on the study. The well-archived registers and copies of histological results allowed 
us to find most of the data of interest. Howerver, this study had some limitations inherent in documentary studies as the main weakness remains the missing data.

\section{Conclusion}

Cancer is very common in rural areas and increases with the age of patients. The characteristics of cancer found did not differ from those observed in urban areas in the DRC and in other developing countries. This study finds the prevalence of prostate cancer in men, while in women, breast and cervical cancer are predominant. The establishment of a cancer registry is necessary in the DRC health system for better epidemiological monitoring of cancer and the surveillance data necessary for the development of cancer control policies and their integration into primary health care.

\section{Conflicts of Interest}

The authors declare no conflicts of interest regarding the publication of this paper.

\section{References}

[1] Bray, F. and Soerjomataram, I. (2015) Chapter 2: The Changing Global Burden of Cancer: Transitions in Human Development and Implications for Cancer Prevention and Control. In: Gelband, H., Jha, P., Sankaranarayanan, R., et al., Eds., Cancer. Disease Control Priorities, 3rd Edition, Vol. 3, The International Bank for Reconstruction and Development/The World Bank, Washington DC. https://www.ncbi.nlm.nih.gov/books/NBK343643/

[2] Zinsoun, C.P., Fourn, L. and Zohounn, T. (1990) Aspects épidémiologiques des cancers au centre national hospitalier et universitaire de Cotonou. Medecine $d$ Afrique Noire, 37, 232-236.

[3] American Cancer Society (2007) Global Cancer Facts \& Figures 2007. American Cancer Society, Atlanta.

[4] Lindsey, A., Torre, L.A., Rebecca, L., Siegel, R.L., Elizabeth, M., Ward, E.M. and Jemal, A. (2015) Global Cancer Incidence and Mortality Rates and Trends-An Update. Cancer Epidemiology, Biomarkers \& Prevention, 25, 16-27. https://doi.org/10.1158/1055-9965.EPI-15-0578

[5] Parkin, D.M., Bray, F.I. and Devesa, S.S. (2001) Cancer Burden in the Year 2000. The Global Picture. European Journal of Cancer, 37, S4-S66. https://doi.org/10.1016/S0959-8049(01)00267-2

[6] Ndongo, J.S., Ntsama Essomba, C.M. and Ongolo-Zogo, P. (2014) Un observatoire pour améliorer l'accès aux médicaments contre les maladies chroniques non transmissibles au Cameroun. Centre pour le développement des bonnes pratiques en santé-Hôpital central Yaoundé, Cameroun.

[7] Chardot, C., Fervers, B., Bey, P., Abbatucci, J.S. and Philip, T. (1995) Standards, options et recommandations pour l'organisation pluridisciplinaire en cancérologie. Bulletin du Cancer, 10, 780-794.

[8] Ferlay, J., Soerjomataram, I., Dikshit, R., Eser, S., Mathers, C., Rebelo, M., Parkin, D.M., et al. (2015) Cancer Incidence and Mortality Worldwide: Sources, Methods and Major Patterns in GLOBOCAN 2012. International Journal of Cancer, 136, E359-E386. https://doi.org/10.1002/ijc.29210 
[9] UICC (2007) Guide pour Organisation d'un Plan National de contrôle du Cancer à l'usage des organisations Non Gouvernementales.

[10] ALIAM (2017) Les cancers en Afrique Francophone en 2017.

http://www.e-cancer.fr/Comprendre-prevenir-depister/Qu-est-ce-qu-un-cancer/Ty pes-de-cancers

[11] Jeune Afrique Santé (2015) 10 choses à savoir sur le cancer en Afrique-4 février.

[12] Mashinda, K.D., Kayembe, K.P. and Mapatano, M.A. (2012) Prévalence du cancer en République Démocratique du Congo: Données anatomopathologiques recueillies aux Cliniques universitaires de Kinshasa et à l'Hôpital Provincial Général de Référence de Kinshasa. Annals of African Medicine, 5, 1087-1093.

[13] Ndahindwa, V., Ngendahayo, L. and Vyankandondera, J. (2012) Aspects epidemiologiques et anatomopathologiques des cancers dans les Centres Hospitaliers Universitaires (CHU) du Rwanda. Revue Médicale Rwandaise, 69, 40-49.

[14] Newton, R., Ngilimana, J. and Grulich, A. (1996) Cancer in Rwanda. International Journal of Cancer, 76, 75-81. https://doi.org/10.1002/(SICI)1097-0215(19960328)66:1<75::AID-IJC14>3.0.CO;2$\underline{\mathrm{A}}$

[15] Parkin, D.M., Whelan, S.L. and Ferlay, J. (2002) Cancer Incidence in Five Continents, Vol. VIII. IARC Press, Lyon.

[16] Parkin, D.M., Ferlay, J. and Hamdi Cherif, M. (2003) Cancer in Africa: Epidemiology and Prevention. IARC Press, Lyon.

[17] Wabinga, H.R., Parkin, D.M. and Wabwire-Mangen, F. (2000) Trends in Cancer Incidence in Kyadondo County, Uganda, 1960-1997. British Journal of Cancer, 82, 1582-1592.

[18] Raharisolo Vololonantenaina, R.C., Pecarrere, J.L. and Roux, J.F. (1998) Le cancer à Madagascar. Expérience de l'Institut Pasteur de Madagascar de début septembre 1992 à fin juin 1996. Bulletin de la Société de Pathologie Exotique, 91, 17-21.

[19] Henderson, B.E., Ross, R.K., Pike, M.C. and Casagrande, J.T. (1982) Endogenous Hormones as a Major Factor in Human Cancer. Cancer Research, 42, 3232-3239.

[20] Osama Koriech, M. and Al-Kuhaymi, R. (1994) Profile of Cancer in Riyadh Armed Forces Hospital. Annals of Saudi Medicine, 14, 187-194.

https://doi.org/10.5144/0256-4947.1994.187

[21] Ngendahayo, P. and Parkin, D.M. (1986) Le cancer au Rwanda: Etude de fréquence relative. Bulletin du Cancer, 73, 155-164.

[22] Bayo, S., Parkin, D.M. and Koumare, A.K. (1990) Cancer in Mali, 1987-1988. International Journal of Cancer, 45, 679-684. https://doi.org/10.1002/ijc.2910450418

[23] Chockunonga, E., Levy, L.M. and Basseit, M.T. (200) Cancer Incidence in the Population of Harare, Zimbabwe: Second Results from the Cancer Registry 1993-1995. International Journal of Cancer, 1, 54-59. https://doi.org/10.1002/(SICI)1097-0215(20000101)85:1<54::AID-IJC10>3.0.CO;2-D

[24] Kadende, P., Engels, D. and Ndoricimpa, J. (1990) Les cancers digestifs au Burundi. Médecine d' Afrique Noire, 37, 552-561.

[25] Banda, C.P. (2001) Cancer Incidence in Blantyre, Malawi 1994-1998. Tropical Medicine \& International Health, 6, 296-304. https://doi.org/10.1046/j.1365-3156.2001.00707.x

[26] Hill, C. (2005) Il est temps de prendre au sérieux la prévention des cancers. Bulletin du Cancer, 102, S14-S21. https://doi.org/10.1016/S0007-4551(15)31213-3 